\title{
The prevalence of abdominal obesity and hypertension amongst adults in Ogbomoso, Nigeria
}

\author{
Authors: \\ Isaac O. Amole ${ }^{1}$ \\ Akintayo D. OlaOlorun ${ }^{1}$ \\ Louis O. Odeigah ${ }^{2}$ \\ Stephen A. Adesina ${ }^{1}$ \\ Affiliations: \\ ${ }^{1}$ Department of Family \\ Medicine, Bowen \\ University Teaching \\ Hospital, Nigeria \\ ${ }^{2}$ Department of Family \\ Medicine, University of \\ Ilorin Teaching Hospital, \\ Nigeria \\ Correspondence to: \\ Isaac Amole \\ Email: \\ amoleio@yahoo.com \\ Postal address: \\ PO Box 15, Ogbomoso \\ 23402, Nigeria \\ Dates: \\ Received: 20 Apr. 2010 \\ Accepted: 09 Aug. 2010 \\ Published: 08 Mar. 2011 \\ How to cite this article: \\ Amole IO, OlaOlorun AD, \\ Odeigah LO, Adesina SA. \\ The prevalence of \\ abdominal obesity and \\ hypertension amongst \\ adults in Ogbomoso, \\ Nigeria. Afr J Prm Health \\ Care Fam Med. 2011;3(1), \\ Art. \#188, 5 pages. \\ doi:10.4102/phcfm. \\ v3i1.188
}

Background: In many developing countries obesity and obesity-related morbidity are now becoming a problem of increasing importance. Obesity is associated with a number of disease conditions, including hypertension, type 2 diabetes mellitus, cardiovascular diseases, cancer, gallstones, respiratory system problems and sleep apnoea.

Objectives: The aim of this study was to determine the prevalence of hypertension and obesity, as classified according to waist circumference (WC), and further to determine whether there was any association between abdominal obesity and hypertension amongst adults attending the Baptist Medical Centre, Ogbomoso, Nigeria.

Method: A cross-sectional descriptive study of 400 adults aged 18 years or older was conducted. Blood pressure and WC measurements were taken and participants completed a standardised questionnaire.

Results: A group of 400 participants were randomly selected (221 women; 179 men), with a mean age of $48.7 \pm 16.6$ years. The overall prevalence of obesity as indicated by WC was $33.8 \%$ $($ men $=8.9 \%$; women $=53.8 \%)$. Women were significantly more sedentary than men $(50.8 \%$ for men vs $62.4 \%$ for women, $p<0.05$ ). Most of the obese participants' families also preferred high-energy foods $(85.2 \%, p>0.05)$. Overall prevalence of hypertension amongst the study population was $50.5 \%$, but without a significant difference between men and women $(52.0 \%$ for men vs $49.3 \%$ for women, $p>0.05$ ). The prevalence of hypertension amongst the obese subset, however, was $60.0 \%$.

Conclusion: Prevalence of abdominal obesity was found to be particularly significant amongst women in this setting and was associated with hypertension, physical inactivity and the consumption of high-energy diets.

\section{Introduction}

In many developing countries obesity and obesity-related morbidity are becoming a problem of increasing importance. ${ }^{1}$ Urbanisation and economic development have led to a nutritional transition characterised by a shift to diets of higher energy content and/or to the reduction of physical activity, resulting in changes in individuals' body composition. ${ }^{1}$ About 1.2 billion people worldwide are overweight and at least 300 million of them are obese. ${ }^{2}$ The World Health Organization (WHO) projects that more than 700 million adults worldwide will be obese by $2015 .^{3}$

Obesity is defined as a condition of abnormal or excessive fat accumulation in the adipose tissue of the body. ${ }^{4}$ Body mass index (BMI), expressed as the ratio between weight (measured in kilogram) and the square of height (in metres), is used to measure the 'degree of fatness'. A BMI between 25 and 29.9 is defined as overweight, whilst a value above or equals 30 is defined as obese. ${ }^{4}$ Normal weight is characterised by a BMI of between 18 and 24.9. A shortcoming of the BMI is that it does not give information about the total fat or fat distribution in the body, which can also affect health. For instance, fat deposited around the abdomen, especially in males, is far more dangerous than fat deposited in other parts of the body because abdominal fat is metabolically active while fat elsewhere may not be. ${ }^{5}$ The benchmark for assessment of abdominal adiposity is the use of imaging techniques, but in large epidemiological studies these methods are impractical because they are arduous and expensive. ${ }^{5}$ Waist circumference (WC), however, is considered a good anthropometric alternative for assessing abdominal adiposity. WC is an aggregate measurement of the actual amount of total and abdominal fat accumulation and is a crucial correlate of metabolic syndromes found amongst obese and overweight patients. ${ }^{5}$ Abdominal overweight is associated with a WC of $94 \mathrm{~cm}$ for men-101 cm for men and $80 \mathrm{~cm}$ for women-87 cm for women, whilest abdominal obesity is associated with a WC measurement exceeding $102 \mathrm{~cm}$ (for men) or $88 \mathrm{~cm}$ (for women). ${ }^{4}$ The major drawback of using WC to assess 
TABLE 1: Blood pressure categories for adults (JNC-7) ${ }^{9}$

\begin{tabular}{lll}
\hline BP classification & SBP $(\mathbf{m m H g})$ & DBP $(\mathbf{m m H g})$ \\
\hline Normal & $<$ or 120 & $<$ or 80 \\
Pre-hypertension & $120-139$ & $80-89$ \\
Stage 1 hypertension & $140-159$ & $90-99$ \\
Stage 2 hypertension & $\geq 160$ & $\geq 100$ \\
\hline
\end{tabular}

Source: JNC-7 report

$\mathrm{BP}$, blood pressure; DBP, diastolic blood pressure; SBP, systolic blood pressure

TABLE 2: Prevalence of abdominal obesity and hypertension.

\begin{tabular}{lll}
\hline Prevelence & Frequency & Percentage \\
\hline Abdominal obesity & & \\
Normal & 194 & 48.5 \\
Overweight & 71 & 17.8 \\
Obese & 135 & 33.8 \\
Hypertension & & \\
Normal & 61 & 15.2 \\
Pre-hypertension & 163 & 40.8 \\
Stage 1 & 94 & 23.5 \\
Stage 2 & 82 & 20.5 \\
\hline
\end{tabular}

abdominal adiposity is that even with a standard protocol, clinicians' measurements may differ.

Obesity is associated with a number of disease conditions, including hypertension, type 2 diabetes mellitus, cardiovascular diseases, cancer, gallstones, respiratory system problems and sleep apnoea. ${ }^{6,7}$ According to the WHO, up to $20 \%$ of the population in developed countries may suffer from obesity-associated hypertension, which may account for $78 \%$ and $65 \%$ of essential hypertension in men and women, respectively. ${ }^{8}$ Hypertension is generally associated with a systolic blood pressure exceeding or equals $140 \mathrm{mmHg}$ or a diastolic blood pressure of $90 \mathrm{mmHg}$ or higher. ${ }^{9}$ Systolic and diastolic blood pressures are used to categorise normal blood pressure, pre-hypertension, stage 1 hypertension and stage 2 hypertension (Table 1).

\section{Setting}

Ogbomoso is located about $100 \mathrm{~km}$ north of Ibadan, capital of the Oyo State in south-west Nigeria. The indigenous people belong to the Yoruba ethnic group, who engage mostly in farming or trading. There are two renowned academic institutions in Ogbomoso (Ladoke Akintola University of Technology and the Nigerian Baptist Theological Seminary), which attract people from other ethnic groups to the city. A government-owned general hospital, a Baptist mission hospital, a few primary health care centres and an increasing number of private hospitals meet the health needs of the people.

\section{Ethical considerations}

The Ethics Committee of the Baptist Medical Centre, Ogbomoso granted approval for the study. Informed consent was also obtained from the participants before commencement of the study.

\section{Method}

The study was conducted at the outpatients clinic of the Baptist Medical Centre, Ogbomoso between January and
July 2008. The hospital is a 200-bed mission hospital that renders primary and secondary health care. It is the referral centre for all other hospitals in Ogbomoso. The aim of this study was to determine the prevalence of hypertension and obesity, as classified according to WC, and whether any association exists between them.

A cross-sectional descriptive survey was used. Consenting participants aged 18 years or older were recruited for the study. Pregnant women, women in the puerperium (up to 6 weeks post-delivery) and patients with ascites or intrabdominal masses (determined through history and physical examination) were excluded from the study.

A systematic sampling method was used to select the participants. The list of patients with appointments at the outpatients clinic was taken as a sample frame, and from a review of records an average of 100 patients were estimated to attend the clinic per day during the period of the study. A sampling fraction of 10 was chosen and according to a simple random sampling method the first subject from every 10 patients on the register was selected to participate. An identification sticker was placed on all selected participants' record cards at the records office and sent to a consulting office designated for the study. The selected subjects were screened and those who met the inclusion criteria were recruited for the study upon obtaining informed consent. The identification sticker remained on each participant's card until completion of the study to avoid repeat selection. This sampling method yielded 400 participants aged 18 years or older.

Demographic information (age, gender, marital status, ethnic group, religion, nationality, occupation, educational status, physical activity, family history of hypertension and family eating habits) was obtained through a pre-tested questionnaire.

WC (in centimetres) was measured using a flexible, nonstretchable tape measure, at the midpoint between the lower rib border and the iliac crest at the end of expiration while participants were standing upright. ${ }^{10}$ Abdominal overweight was defined as a WC between $94 \mathrm{~cm}$ and $101 \mathrm{~cm}$ for men and between $80 \mathrm{~cm}$ and $87 \mathrm{~cm}$ for women, while abdominal obesity was defined as a WC $\geq 102 \mathrm{~cm}$ and $\geq 88 \mathrm{~cm}$ for men and women, respectively. ${ }^{4}$

Blood pressure was measured using an Accoson Dekamet mercury sphygmomanometer (Accoson, Essex) with an appropriate cuff size and a Littmann stethoscope (3M, Brookings). Blood pressure was measured in the right arm after at least $15 \mathrm{~min}$ of rest and while participants were sitting down. ${ }^{11}$ The cuff (about $12.5 \mathrm{~cm}$ wide) was applied evenly and snugly around the bare arm, with the lower edge $2.5 \mathrm{~cm}$ above the antecubital fossa. A thigh cuff (about 15 $\mathrm{cm}$ wide) was used for obese subjects. The cuff was inflated rapidly to about $30 \mathrm{mmHg}$ above the level at which the radial 
pulse was no longer palpable, followed by slow deflation. The investigator listened with a stethoscope placed over the brachial artery in the antecubital fossa while deflating the cuff. Three readings, at least $2 \mathrm{~min}$ apart, were taken for each subject and the mean of the second and third readings were used for analysis. ${ }^{11}$ The systolic pressure was taken as the first-phase sound of Korotkoff and the diastolic pressure was taken as the fifth-phase sound of Korotkoff. The observed value was recorded to the nearest $2 \mathrm{mmHg}$. Hypertension was noted if systolic blood pressure exceeded $140 \mathrm{mmHg}$ or diastolic blood pressure exceeded $90 \mathrm{mmHg},{ }^{9}$ or upon selfreport of a medical diagnosis of hypertension or current treatment for hypertension with prescription medication. ${ }^{12}$ Participants who engaged in 30 minutes' leisure-time physical activity (walking, fitness training or sports) at least three times per week were classified as physically active. ${ }^{13}$

Participants were classified with regard to social class based on their occupation, as per the Registrar General's scale of social classes: ${ }^{14}$

- Class 1: Professional, for example lawyers, doctors, accountants

- Class 2: Intermediate, for example teachers, nurses, managers

- Class 3N: Skilled non-manual, for example typists, shop assistants, telephone operators

- Class 3M: Skilled manual, for example mineworkers, bus drivers, cooks, artisans

TABLE 3: Association between abdominal adiposity, gender, family menu, social class and hypertension.

\begin{tabular}{|c|c|c|c|c|c|c|c|c|c|c|}
\hline \multirow[t]{3}{*}{ Variables } & \multicolumn{8}{|c|}{ Abdominal adiposity } & \multirow[t]{3}{*}{$\chi^{2}$} & \multirow[t]{3}{*}{$p$-value } \\
\hline & \multicolumn{2}{|c|}{ Normal } & \multicolumn{2}{|c|}{ Overweight } & \multicolumn{2}{|c|}{ Obese (\%) } & \multicolumn{2}{|c|}{ Total (\%) } & & \\
\hline & $n$ & $\%$ & $n$ & $\%$ & $n$ & $\%$ & $n$ & $\%$ & & \\
\hline Age range & & & & & & & & & 64.825 & 0 \\
\hline $18-19$ & 5 & 100.0 & 0 & 0.0 & 0 & 0.0 & 5 & 1.3 & - & - \\
\hline $20-29$ & 47 & 83.9 & 6 & 10.7 & 3 & 5.4 & 56 & 14.0 & - & - \\
\hline $30-39$ & 34 & 51.5 & 12 & 18.2 & 20 & 30.3 & 66 & 16.5 & - & - \\
\hline $40-49$ & 20 & 27.8 & 11 & 15.3 & 41 & 56.9 & 72 & 18.0 & - & - \\
\hline $50-59$ & 27 & 32.5 & 19 & 22.9 & 37 & 44.6 & 83 & 20.7 & - & - \\
\hline $60-69$ & 35 & 48.6 & 16 & 22.2 & 21 & 29.2 & 72 & 18.0 & - & - \\
\hline$\geq 70$ & 27 & 58.7 & 6 & 13.0 & 13 & 28.3 & 46 & 11.5 & - & - \\
\hline Gender & & & & & & & & & 117.72 & 0 \\
\hline Male & 139 & 77.7 & 24 & 13.4 & 16 & 8.9 & 179 & 44.8 & - & - \\
\hline Female & 56 & 25.4 & 46 & 20.8 & 119 & 53.8 & 221 & 55.2 & - & - \\
\hline \multicolumn{11}{|l|}{ Family menu } \\
\hline Fat & 0 & 0.0 & 0 & 0.0 & 0 & 0.0 & 0 & 0.0 & - & - \\
\hline Total & 195 & 100.0 & 70 & 100.0 & 135 & 100.0 & 400 & 100.0 & 5.874 & 0.209 \\
\hline \multicolumn{11}{|l|}{ Social class } \\
\hline Class 1 & 3 & 1.5 & 1 & 1.4 & 0 & 0.0 & 4 & 1.0 & - & - \\
\hline Class 2 & 37 & 19.0 & 18 & 25.7 & 32 & 23.7 & 87 & 21.8 & - & - \\
\hline Class $3 \mathrm{~N}$ & 53 & 27.2 & 34 & 48.6 & 84 & 62.2 & 171 & 42.7 & - & - \\
\hline Class 3M & 15 & 7.7 & 4 & 5.7 & 3 & 2.2 & 22 & 5.5 & - & - \\
\hline Class 4 & 43 & 22.1 & 4 & 5.7 & 3 & 2.2 & 50 & 12.5 & - & - \\
\hline Class 5 & 44 & 22.6 & 9 & 12.9 & 13 & 9.6 & 66 & 16.5 & - & - \\
\hline Total & 195 & 100.0 & 70 & 100.0 & 135 & 100.0 & 400 & 100.0 & 68.401 & 0 \\
\hline \multicolumn{11}{|l|}{ Hypertension } \\
\hline Hypertensive & 85 & 43.6 & 36 & 51.4 & 81 & 60.0 & 202 & 50.5 & - & - \\
\hline Normotensive & 110 & 56.4 & 34 & 48.6 & 54 & 40.0 & 198 & 49.5 & - & - \\
\hline Total & 195 & 100.0 & 70 & 100.0 & 135 & 100.0 & 400 & 100.0 & 8.623 & 0.013 \\
\hline Pre-hypertension & 86 & 44.3 & 28 & 39.4 & 49 & 36.3 & 163 & 40.8 & - & - \\
\hline Stage 1 & 40 & 20.6 & 13 & 18.4 & 41 & 30.4 & 94 & 23.5 & - & - \\
\hline Stage 2 & 36 & 18.6 & 15 & 21.1 & 31 & 23.0 & 82 & 20.5 & - & - \\
\hline Total & 194 & 100.0 & 71 & 100.0 & 135 & 100.0 & 400 & 100.0 & 10.192 & 0.117 \\
\hline \multicolumn{11}{|l|}{ Fast food } \\
\hline Rarely & 135 & 69.2 & 47 & 67.1 & 97 & 71.9 & 279 & 69.8 & - & - \\
\hline Occasionally & 58 & 29.7 & 21 & 30.0 & 36 & 26.7 & 115 & 28.7 & - & - \\
\hline Very often & 2 & 1.1 & 2 & 2.9 & 2 & 1.4 & 6 & 1.5 & - & - \\
\hline Total & 195 & 100.0 & 70 & 100.0 & 135 & 100.0 & 400 & 100.0 & 1.622 & 0.805 \\
\hline \multicolumn{11}{|l|}{ Physical activity } \\
\hline Active & 93 & 47.9 & 30 & 42.3 & 48 & 35.6 & 171 & 42.7 & - & - \\
\hline Inactive & 101 & 52.1 & 41 & 57.7 & 87 & 64.4 & 229 & 57.3 & - & - \\
\hline Total & 194 & 100.0 & 71 & 100.0 & 135 & 100.0 & 400 & 100.0 & 4.996 & 0.082 \\
\hline
\end{tabular}

$X^{2}$, Chi-square; $n$, Given as means of number 
- Class 4: Partly skilled (manual), for example farm workers, bus conductors

- Class 5: Unskilled, for example cleaners, labourers.

Data were analysed with the statistical package for social sciences, version 13. (SPSS 13).

\section{Results}

The mean age of the sample was $48.7 \pm 16.6$ years and there were more female $(55.3 \%)$ than male participants $(44.8 \%)$. Table 2 shows that the overall prevalence of obesity as determined according to WC was $33.8 \%$. The prevalence of stage 1 and stage 2 hypertension was $23.5 \%$ and $20.5 \%$, respectively, while the prevalence of pre-hypertension was $40.8 \%$.

The association between abdominal adiposity, hypertension and demographic and lifestyle variables is shown in table 3. Obesity increased with age, but was most prevalent amongst the age group $40-49$ years. The prevalence of obesity amongst men was $8.9 \%$ and $53.8 \%$ amongst women $(p<0.05)$, and almost two-thirds $(64.4 \%)$ of obese participants were physically inactive $(p>0.05)$. The overwhelming majority of obese participants' families $(85.2 \%)$ preferred to consume starchy foods $(p>0.05)$ although the majority of the obese participants $(71.9 \%)$ indicated to eat fast food only rarely $(p>0.05)$. More than half the obese participants $(62.2 \%)$ were from social class $3 \mathrm{~N}(p<0.05)$. Hypertension increased with age and the prevalence of hypertension amongst the study population was $50.5 \%$. The prevalence of hypertension amongst the obese participants was $60.0 \%$. The prevalence of stage 1 and stage 2 hypertension amongst the obese participants was $30.4 \%$ and $23.0 \%$, respectively.

TABLE 4: Gender, physical activity and mean values for age and waist circumference.

\begin{tabular}{|c|c|c|c|c|c|c|c|c|}
\hline \multirow[t]{2}{*}{ Physical activity } & \multicolumn{2}{|c|}{ Male } & \multicolumn{2}{|c|}{ Female } & \multicolumn{2}{|c|}{ Total } & \multirow[t]{2}{*}{$\chi^{2}$} & \multirow[t]{2}{*}{$p$-value } \\
\hline & $n$ & $\%$ & $n$ & $\%$ & $N$ & $\%$ & & \\
\hline Active & 88 & 49.2 & 83 & 37.6 & 171 & 42.7 & - & - \\
\hline Inactive & 91 & 50.8 & 138 & 62.4 & 229 & 57.3 & - & - \\
\hline Total & 179 & 100.0 & 221 & 100.0 & 400 & 100.0 & 4.442 & 0.02 \\
\hline
\end{tabular}

Variables

Age (years) $\quad 49.3 \pm 18.1 \quad 48.1 \pm 15.3 \quad 48.7 \pm 16.7$

$\mathrm{WC}(\mathrm{cm})^{+} \quad 84.1 \pm 12.7 \quad 90.4 \pm 14.6 \quad 87.6 \pm 14.1$

$\chi^{2}$, Chi- square; +WC (cm), waist circumference; $n$, Given as means of number; $n$, Given as means of total number.

TABLE 5: Association between hypertension, age and gender

\begin{tabular}{|c|c|c|c|c|c|c|}
\hline \multirow[t]{2}{*}{ Variables } & \multicolumn{2}{|c|}{ Hypertensive } & \multicolumn{2}{|c|}{ Normotensive } & \multirow[t]{2}{*}{$\chi^{2}$} & \multirow[t]{2}{*}{$p$-value } \\
\hline & $n$ & (\%) & $n$ & (\%) & & \\
\hline Age range & & & & & 51.217 & 0 \\
\hline 18-19 & 1 & 20.0 & 2 & 80.0 & - & - \\
\hline $20-29$ & 12 & 21.4 & 44 & 78.6 & - & - \\
\hline 30-39 & 20 & 30.3 & 46 & 69.7 & - & - \\
\hline $40-49$ & 41 & 56.9 & 31 & 43.1 & - & - \\
\hline $50-59$ & 47 & 56.6 & 36 & 43.4 & - & - \\
\hline $60-69$ & 56 & 63.9 & 26 & 36.1 & - & - \\
\hline$\geq 70$ & 35 & 76.1 & 11 & 23.9 & & \\
\hline Gender & & & & & 0.274 & 0.6 \\
\hline Male & 93 & 52.0 & 86 & 48.0 & - & - \\
\hline Female & 109 & 49.3 & 112 & 50.7 & - & - \\
\hline
\end{tabular}

$\chi^{2}$, Chi- square; $n$, Given as means of number
Study variables are summarised according to gender in Tables 4 and 5. The mean WC amongst males was $84.1 \pm 12.7 \mathrm{~cm}$ and $90.4 \pm 14.6 \mathrm{~cm}$ amongst females $(87.6 \pm 14.1 \mathrm{~cm}$ over the entire group). The prevalence of physical inactivity amongst the participants was $57.3 \%$ $(62.4 \%$ for females and $50.8 \%$ for males, $p<0.05)$.

The prevalence of hypertension amongst female participants was $49.3 \%$ compared to $52.0 \%$ amongst males $(p>0.05)$ as shown in table 5 .

\section{Discussion}

WC measurements from this study show that obesity increased with age, but peaked amongst participants between 40-years and 49 years of age. This is similar to the finding of Siminialayi, Emem-Chioma and Dapper ${ }^{15}$ in Rivers State, Nigeria, which showed that abdominal obesity was more common amongst subjects older than 40 years. The prevalence of obesity as determined according to WC measurements (33.8\%) is comparable to results from Okrika, Rivers State, Nigeria ${ }^{15}$ (31.7\%) and Cotonou, Benin Republic $^{16}$ (32.0\%). Rguibi and Belahsen, ${ }^{17}$ however, found the prevalence of abdominal obesity amongst women in Sahraoui, Morocco to be $76.0 \%$, which is higher than what was found in the present study amongst the women (53.8\%).

The high prevalence of physical inactivity amongst women in this study may be one of the factors that could be responsible for their high prevalence of obesity. In a study regarding the association between measures and determinants of obesity in African women, Kruger, Venter, Vorster and Margetts ${ }^{18}$ found that physical inactivity showed the strongest association with measures of obesity. Their findings are in line with those of Afolabi, Addo and Sonibare, ${ }^{19}$ who conducted a study in Abeokuta, Ogun State, Nigeria. In addition, consumption of high-energy diets is one of the major contributing factors to the development of obesity, as underlined by our finding that the majority of obese participants' families (85.2\%) preferred starchy food. However, contrary to the findings of Fezue, Minkoulou, Balkau, et al. ${ }^{20}$ where obesity was strongly associated with high socio-economic status, more than half $(62.2 \%)$ of the participants classified as obese here fell in social class $3 \mathrm{~N}$. This observation may be due to low representation of participants from social class 1 in this study.

This study also showed that the prevalence of hypertension increases with age, with participants aged 70 years or older showing the highest prevalence $(76.1 \%)$ of hypertension $(p<0.05)$. This is not surprising because it has been established that age is a predisposing factor for the development of essential hypertension. ${ }^{21}$ Our findings are in line with those of Olatunbosun, Kaufman, Cooper and Bella, ${ }^{21}$ who found that age is a risk factor for the development of hypertension in the urban black population in Ibadan, Nigeria. The overall prevalence of hypertension amongst our study population was $50.5 \%$, which may be attributed to the specific setting; hypertension is one of the leading disease entities at the Baptist Medical Centre. The prevalence is, however, higher than in earlier studies in Ghana and elsewhere in Nigeria, where the 
prevalence of hypertension was found to be between $10.3 \%$ and $26.8 \% .22,23,24$ The fact that these studies were community based may be one of the reasons for observing lower overall prevalence of hypertension. Using different cut-off points for hypertension may also have contributed to the different prevalence rates of hypertension observed in earlier studies. Olatunbosun et al. ${ }^{21}$ defined hypertension as systolic or diastolic blood pressure $\geq 160 / 95 \mathrm{mmHg}$, while the cut-off in this study was $\geq 140 / 90 \mathrm{mmHg}$. The prevalence of prehypertension $(40.8 \%)$ was much higher than that of stage 1 (23.5\%) and stage $2(20.0 \%)$ hypertension. Several studies have shown lifestyle modification, which is the main treatment modality in pre-hypertension, to be effective at preventing hypertension and lowering the risk of blood pressure-related clinical complications in the whole population. ${ }^{9,25}$ Therefore, lifestyle modification needs to be promoted amongst patients at Ogbomoso in order to prevent participants who presented with pre-hypertension from progressing to stage 1 or stage 2 .

The higher prevalence of hypertension in men despite a much higher rate of abdominal obesity in women is similar to the findings of Olatunbosun et al. ${ }^{21}$ in Ibadan, Nigeria. This finding is not surprising in a Black population because it has been documented that men are predisposed to developing hypertension in most Black populations. ${ }^{21}$

The study showed that hypertension was strongly associated with obesity in Ogbomoso, although the symptoms suggest mostly pre-hypertension, rather than having progressed already to stage 1 or stage 2 .

\section{Conclusion}

The findings from this study suggest that abdominal obesity in patients presenting at this health care facility in Ogbomoso is particularly significant amongst women and is associated with hypertension, physical inactivity and the consumption of high-energy diets. Measurement of WC requires only the use of a tape measure and therefore most clinics in developing countries should be able to make WC measurement a routine procedure, rather than calculating BMIs, to screen for obesity. This will help to identify patients at risk of developing obesity early and instituting measures such as physical exercise that will lead to a reduction in waist sizes before complications associated with obesity can develop.

Because patients are likely to be already familiar with their waist sizes, it will be easier for them to learn how to measure and interpret their WC, rather than calculating a BMI, of which interpretation is likely to be an abstract concept. People who appreciate the dangers associated with large waists can then institute measures such as increasing physical exercise and adjusting their diet to get their waists back to normal, and thus reduce their risks of disease conditions associated with obesity.

\section{References}

1. Pasquet P, Temgoua LS, Melaman-Sego F, Froment A, Rikong-Adie H. Prevalence of overweight and obesity for urban adults in Cameroon. Ann Hum Biol. 2003;30(5):551-562.

2. World Health Organization. Global strategy on diet, physical activity and health [document on the Internet]. World Health Organization; 2004 [cited 2008 Oct 22]. Available from: http://www.who.int/dietphysicalactivity/strategy/eb11344/ strategy_english_web.pdf

3. World Health Organization. Obesity and overweight [homepage on the Internet]. c2006 [updated 2010; cited 2010 Dec 13].Available from: http://www.who.int/ mediacentre/factsheets/fs311/en/

4. The European Food Information Council. Obesity and overweight [homepage on the Internet]. c2006 [updated 2010 Dec 13; cited 2010 Dec 13]. Available from: http://www.eufic.org/article/en/expid/basics-obesity-overweight/

5. Okosun IS, Rotimi CN, Forrester TE, et al. Predictive value of abdominal obesity cut-off points for hypertension in Blacks from West African and Caribbean island nations. Int J Obes. 2000;24(2):180-186.

6. Puepet $\mathrm{FH}$, Zoakah Al, Chuhwak EK. Prevalence of overweight and obesity among urban Nigeria adults in Jos. Highland Med Res J. 2002;1(1):13-16.

7. Puoane T, Fourie JM, Shapiro M, Rosling L, Tshaka NC, Oelefse A. 'Big is beautiful' - an exploration with urban black community health workers in a South African township. South African J Clin Nutr. 2005;18(1):8-15.

8. Ali AT, Crowther NJ.Health risks associated with obesity. J Endocrinol, Metabol and Diabetes S Af. 2005;10(2):56-61.

9. Joint National Committee on Prevention, Detection, Evaluation, and Treatment of High Blood Pressure. The seventh report of the Joint National Committee on Prevention, Detection, Evaluation, and Treatment of High Blood Pressure [document on the Internet]. US Department of Health and Human Services; 2004 [cited 2009 Mar 20]. Available from: http//www.nhlbi.nih.gov/guidelines/ 2004 [cited 2009 Mar 20].

10. Sunil KA, Anoop M, Priyanka A, Amit B, Ruchika $G$, Naval KV, et al. Waist circumference measurement by site, posture, respiratory phase, and meal time: Implications for methodology. Obesity. 2009;17(5):1056-1061. doi:10.1038/ Implications for methodology.
oby.2008.635, PMid:19165166

11. Gus $M$, Fuchs SL, Moreira LB, Moraes RS, Wiehe M, Silva AF, et al. Association between different measurements of obesity and the incidence of hypertension. Am J Hypertens. 2004;17(1):50-53.

12. Erhun WO, Olayiwola G, Agbani EO, Omotoso NS. Prevalence of hypertension in a university community in South West Nigeria. Afr J Biomed Res. 2005;8(1):15-19.

13. US Department of Health and Human Services. Physical activity fundamental to preventing diseases [homepage on the Internet]. c2002 [updated 2002 June; cited 2008 Oct 17]. Available from: http://aspe.hhs.gov/health/reports/physicalactivity

14. Rose D. Official social classifications in the UK. Social Research Update [seria online]. 1995 [cited 2008 Oct 17]; 9(July). Available from: http://sru.soc.surrey ac.uk/SRU9.html

15. Siminialayi IM, Emem-Chioma PC, Dapper DV. The prevalence of obesity as indicated by BMI and waist circumference among Nigerian adults attending Family Medicine clinics as outpatients in Rivers State. Niger J Med. 2008;17(3):340-345.

16. Sodjinou R, Agueh V, Fayomi B, Delisle H. Obesity and cardio-metabolic risk factors in urban adults of Benin: relationship with socio-economic status, urbanisation, in urban adults of Benin: relationship with socio-economic status, urbanisation, and lifestyle patterns. BMC Public Heat:18318907, PMCid:2315643

17. Rguibi M, Belahsen R. Overweight and obesity among urban Sahraoui women of South Morocco. Ethn Dis. 2004;14(4):542-7.

18. Margetts BM, Kruger HS, Venter CS, Vorster HH. Physical inactivity is the major determinant of obesity in black women in the North West Province, South Africa: the THUSA study. Nutrition. 2002;18(5):422-427.

19. Afolabi WA, Addo AA, Sonibare MA. Activity pattern, energy intake and obesity among Nigerian urban market women. Int J Food Sci Nutr. 2004;55(2):85-90.

20. Fezue L, Minkoulou E, Balkau B, Kengne A, Awah P, Unwin N, et al. Association between socioeconomic status and adiposity in urban Cameroon. Int J Epid. 2006;35(1):105-111.

21. Olatunbosun ST, Kaufman JS, Cooper RS, Bella AF. Hypertension in a black population: prevalence and biosocial determinants of high blood pressure in a group of urban Nigerians. J Hum Hypertens. 2000;14:249-257. doi:10.1038/ sj.jhh.1000975, PMid:10805050

22. Omuemu VO, Okojie $\mathrm{OH}$, Omuemu CE. Blood pressure pattern and prevalence of hypertension in a rural community in Edo State. JMBR. 2006;5(2):79-86.

23. Bektas MY, Erkan MS, Esra Y. Which anthropometric measurement is most closely related to elevated blood pressure? BMC Fam Pract. 2005;22(5):541-547.

24. Kosugi T, Nakagawa T, Kamath D, Johnson RJ. Uric acid and hypertension: an agerelated relationship? J Hum Hypertens 2009;23(2):75-6. doi:10.1038/jhh.2008.110, PMid:18754017

25. Isuezo SA. Systemic hypertension in blacks. An overview of current concepts of pathogenesis. Nigerian Postgraduate Medical Journal. 2003;10:144-153. 